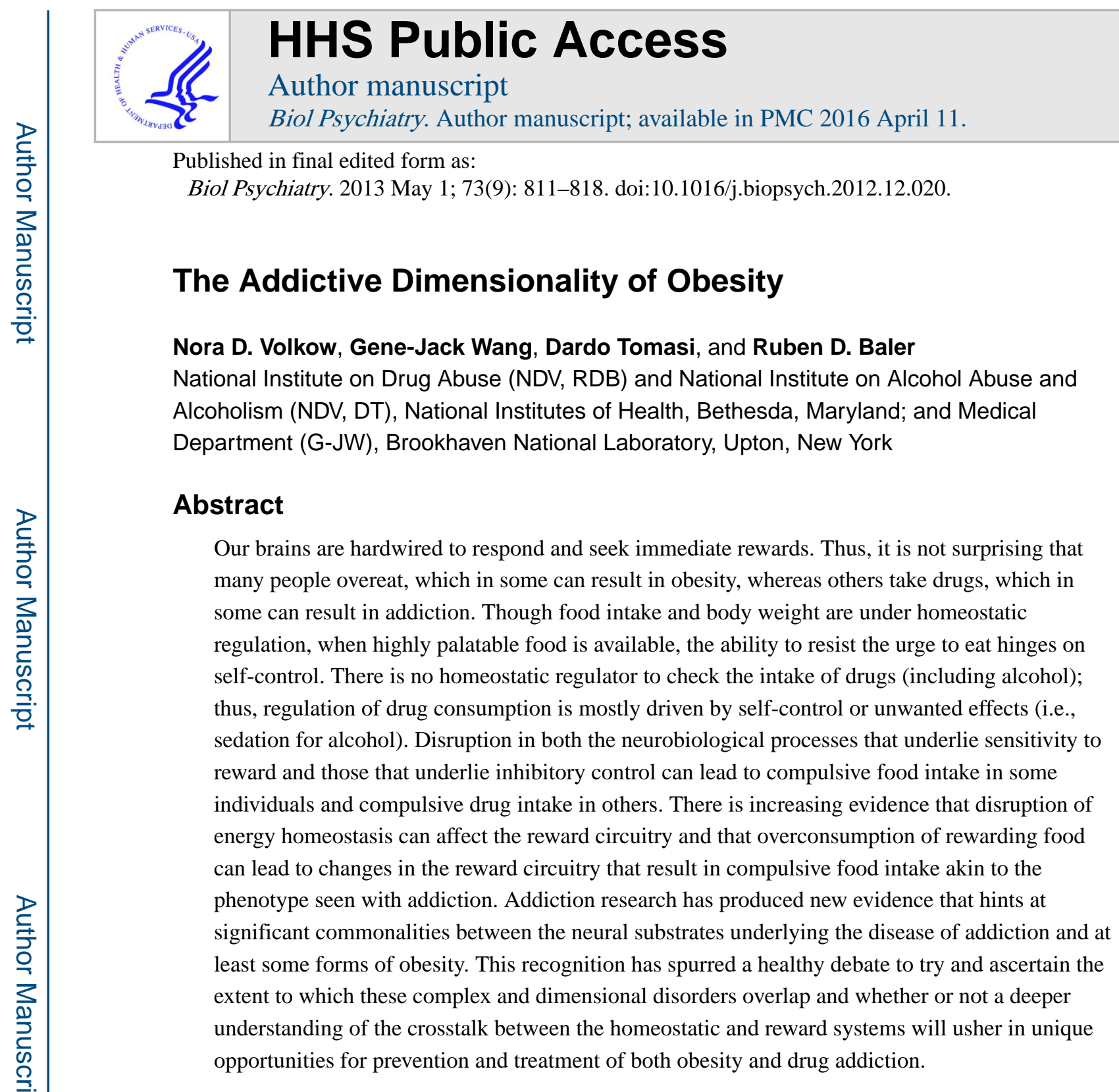

\title{
Keywords
}

Dopamine; drug addiction; obesity; prefrontal cortex; reward; self-control

Both addiction and obesity reflect imbalances in the responses of the brain to rewarding stimuli in the environment. For obesity, this imbalance can be triggered by endocrinological abnormalities that change the energetic threshold and modify the sensitivity to food rewards. However, obesity can also result from easy access to highly palatable food, excessive consumption of which can affect homeostatic signaling and disrupt the sensitivity to food reward. Repeated consumption of a drug, on the other hand, can directly disrupt the reward circuit, its main pharmacologic target. Thus, the dopamine (DA) system, through the mesoaccumbens/mesolimbic (reward and emotions), mesostriatal (habits, routines, and

Address correspondence to Nora D. Volkow, M.D., National Institute on Drug Abuse, 6001 Executive Boulevard, Mail Drop Code: 9581, Suite 5274, Bethesda, MD 20892; nvolkow@nida.nih.gov.

The authors report no biomedical financial interests or potential conflicts of interest. 
movement), and mesocortical (executive function) pathways, is a common substrate in the neurobiology of both disorders (Figure 1).

We propose that these two diseases share neurobiological processes that, when disrupted, can result in compulsive consumption, while also involving unique neurobiological processes. We present evidence of shared neurobiological substrates and do not claim that obesity is the result of food addiction but rather that food reward plays a critical role in overeating and obesity, referring to it as the dimensional component of obesity.

\section{Genetic Overlaps}

Social and cultural factors contribute to the obesity epidemic. However, individual factors also help determine who will become obese in these environments. Though genetic studies have revealed point mutations that are overrepresented among obese individuals, obesity is largely thought to be under polygenic control. Indeed, the most recent whole genome-wide association study conducted in 249,796 individuals of European descent identified 32 loci associated with body mass index (BMI). However, these 32 loci explained only $1.5 \%$ of the BMI variance $(1,2)$, a situation that is unlikely to improve with larger samples because of the complex interactions between biological and environmental factors. This is particularly true whenever high-calorie content food is widely available, not just as a source of nutrition, but also as a strong reward that, by itself, promotes eating.

Perhaps, broadening the scope of what we understand by genetic risk for obesity beyond genes linked to energy homeostasis (3) to include genes that modulate our response to the environment would increase the percentage of the BMI variance explained by genes. For example, genes that influence personality could contribute to obesity if they erode the perseverance needed for sustained physical activity. Similarly, genes that modulate executive control, including self-control, may help counteract the risk for overeating in food-rich environments. This could explain the association of obesity with genes involved with DA neurotransmission, such as the DRD2 Taq I A1 allele, which has been associated with addiction (4). Similarly, there are genes at the intersection between reward and homeostatic pathways, like the cannabinoid receptor 1 ( $C N R I)$ gene, variations in which have been associated with BMI and obesity risk by most studies (5), as well as with addiction (6). And, let us also remember in this context that endogenous opioids are involved in hedonic responses to food and to drugs and that the functional $\mathrm{A} 118 \mathrm{G}$ polymorphism in the $\mu$-opioid receptor gene (OPRMI) has been associated with vulnerability for binge-eating disorders (7) and alcoholism (8).

\section{Molecular Overlaps: Focus on Dopamine}

The decision to eat (or not) is not only influenced by the internal state of the caloric equation but also by nonhomeostatic factors, such as food palatability and environmental cues that trigger conditioned responses. The past decade has uncovered numerous molecular and functional interactions between the homeostatic and reward levels of food regulation. Specifically, several hormones and neuropeptides involved in energy homeostasis influence the DA reward pathway (9). Overall, homeostatic orexigenic signals increase the activity of ventral tegmental area (VTA) DA cells when exposed to food stimuli, whereas anorexigenic 
ones inhibit DA firing and decrease DA release (10). Moreover, neurons in VTA and/or nucleus accumbens (NAc) express glucagon-like peptide-1 $(11,12)$, ghrelin $(13,14)$, leptin $(15,16)$, insulin (17), orexin (18), and melanocortin receptors (19). Therefore, it is not surprising that these hormone/peptides can influence the rewarding responses to drugs of abuse. Such interactions could explain the findings of attenuated responses to the rewarding effects of drugs in animal models of obesity (20). Similarly, human studies found an inverse relationship between BMI and illicit drug use (21) and a lower risk for substance use disorders in obese individuals (22), including lower rates of nicotine (23) and marijuana (24) abuse. Moreover, interventions that decrease BMI and reduce plasma levels of insulin and leptin enhance the sensitivity to psychostimulant drugs (25), and bariatric surgery for obesity is associated with an increased risk for relapse to alcohol abuse and alcoholism (26). Taken together, these results strongly suggest the possibility that food and drugs may be competing for overlapping reward mechanisms.

The phenomenological and neurobiological overlaps between obesity and addiction can be predicted on the basis that drugs of abuse tap into the same neuronal mechanisms that modulate the motivation and drive to seek and consume food (27). Since drugs activate brain reward pathways more potently than food, this helps explain (together with homeostatic satiety mechanisms) the greater ability of drugs to induce loss of control and compulsive consummatory behavior. Brain DA pathways, which modulate the behavioral responses to environmental stimuli, play central roles in obesity (also in addiction). Dopamine neurons (both in VTA and substantia nigra) modulate not only reward but also the motivation and sustainability of effort necessary to accomplish behaviors needed for survival. Indeed, DAdeficient mice die of starvation, likely as a result of a decreased motivation to consume the food, and replenishing the dorsal striatum with DA restores feeding and rescues them (28). There is another DA pathway (tuberoinfundibular pathway) that projects from the hypothalamus to the pituitary gland, but we are not considering it here because it has not yet been implicated in the rewarding effects of drugs (29), even though it can be affected by drugs of abuse (30). To achieve its functions, DA neurons receive projections from brain regions involved with autonomic responses (hypothalamus, insula), memory (hippocampus), emotional reactivity (amygdala), arousal (thalamus), and cognitive control (prefrontal cortex) through a diverse set of neurotransmitters and peptides (31). Predictably then, many neurotransmitters implicated in drug-seeking behaviors are also implicated in food intake (9).

Of all the signals implicated in the effects of food and drugs, DA has been the most thoroughly investigated. Experiments in rodents have shown, for example, that DA signals through both D1 receptors and D2 receptors (D2R) in the dorsal striatum are necessary for feeding and other eating-related behaviors (28). For example, upon first exposure to a food reward, the firing of DA neurons in the VTA increases with a resulting increase in DA release in the NAc (32). With repeated exposure, the DA neurons stop firing when receiving the food and fire instead when exposed to the stimulus that predicts food delivery (33). Moreover, since the increases in DA induced by the conditioned stimulus predict the behavioral price the animal is willing to pay to receive it, this will ensure that the motivational drive (fueled by DA signaling) occurs before the animal is eating the food itself. Interestingly, when the cue does not lead to the expected food reward, DA neuron 
activity is inhibited, decreasing the incentive value for the cue (extinction). Animal models of both food and drug reward have shown that after extinction, the behavior for drug or food consumption can be triggered either by exposure to the cue, the reward, or a stressor (34). This vulnerability to relapse has been extensively studied in animal models of drug administration and reflects neuroplastic changes in alpha-amino-3-hydroxy-5-methyl-4isoxazole-propionic acid and $N$-methyl-D-aspartate receptor glutamatergic signaling (35). For drug reward, studies have also shown that an imbalance between D1 receptor signaling (enhanced) and D2 receptor signaling (decreased) facilitates compulsive drug intake (36); one could predict that a similar imbalance may favor compulsive food intake. This possibility is consistent with a recent report in which a D1-like antagonist blocked and a D2like antagonist increased the reinstatement of food-seeking behavior (37).

Taken together, these results suggest that the homeostatic circuitry has evolved to take advantage of the dopaminergic circuitry to imbue feeding behaviors not only with the conditioning/rewarding properties subsumed initially by the ventral striatum but also with the subsequent utilization of dorsal striatum outputs to cortical structures directly involved in coupling motivation with the motor responses needed for goal-directed behaviors (38).

\section{Neurocircuitry and Behavioral Overlaps}

The overwhelming urge to seek and consume the drug in addiction involves disruption not only of the reward circuitry but also of other circuits, including interoception, inhibitory control, mood and stress regulation, and memory (39). It can be argued that this neurocircuitry model of addiction also applies to certain types of obesity.

\section{Reward, Conditioning, and Motivation}

Drugs of abuse work by activating the DA reward circuit, which, if chronic, in vulnerable individuals, can result in addiction. Certain foods, particularly those rich in sugars and fat, are also potently rewarding (40) and can trigger addictive like behaviors in laboratory animals (41) and humans (27). Indeed, high-calorie foods can promote overeating (i.e., eating that is uncoupled from energetic needs) and trigger learned associations between the stimulus and the reward (conditioning). This property of palatable foods used to be evolutionarily advantageous when food was scarce, but in environments where such foods are plentiful and ubiquitous, it is a dangerous liability. Thus, palatable foods, like drugs of abuse, represent a powerful environmental trigger, which, in vulnerable individuals, has the potential to facilitate or exacerbate the establishment of uncontrolled behaviors.

In humans, the ingestion of palatable food releases DA in the striatum in proportion to the ratings of meal pleasantness (42) and activates reward circuitry (43). Consistent with preclinical studies, imaging studies have also shown that anorexigenic peptides (e.g., insulin, leptin, peptide YY) decrease the sensitivity of the brain reward system to food reward, whereas orexigenic ones (e.g., ghrelin,) increase it [see review (44)]. Surprisingly, both addicted and obese subjects exhibit less activation of reward circuits when given the drug or the palatable food, respectively (45). This is counterintuitive since the increases in DA are believed to mediate the rewarding values of drug and food rewards; hence, blunted DA responses during consumption should predict behavioral extinction. Since this is not what is 
seen in the clinic, it was suggested that blunted DA activation by consumption (of drug or food) could trigger overconsumption to compensate for the blunted response of the reward circuit (46). Preclinical studies showing that decreased DA activity in VTA results in a dramatic increase in the consumption of high-fat foods (47) partially support this hypothesis.

In contrast to the blunted reward responses during reward consumption, both addicted and obese subjects show sensitized responses to conditioned cues predictive of drug or food reward. The magnitude of these DA increases in addicted subjects predicts the intensity of cue-induced cravings (48), and in animals, they predict the effort that an animal is willing to exert to get the drug (49). Compared with normal-weight individuals, obese individuals observing pictures of high-calorie food (stimuli to which they are conditioned) showed increased activation in regions of the reward and motivation circuits (NAc, dorsal striatum, orbitofrontal cortex [OFC], anterior cingulate cortex [ACC], amygdala, hippocampus, and insula) (50). Similarly, in obese individuals with binge-eating disorder, higher DA releasewhen exposed to food cues_- was associated with the severity of the disorder (51).

The extensive glutamatergic afferents to DA neurons from regions involved in the processing of reward (NAc), conditioning (amygdala, hippocampus, prefrontal cortex), and salience attribution (orbitofrontal cortex) modulate their activity in response to conditioned cues (31). More specifically, projections from the amygdala, hippocampus, and OFC to DA neurons and to NAc are involved in conditioned responses to food (52) and drugs (53). Indeed, imaging studies showed that when nonobese male subjects were asked to inhibit their craving for food when exposed to food cues, they decreased activity in amygdala, OFC, hippocampus, insula, and striatum; and OFC decreases were associated with reductions in food craving (54). A similar inhibition of OFC activity (and NAc) was observed in cocaine abusers when they were asked to inhibit their drug craving during exposure to cocaine cues (55). However, compared with food cues, drug cues are more powerful triggers of reinforcerseeking behavior following a period of abstinence. Thus, once extinguished, drug-reinforced behaviors are far more susceptible to stress-induced reinstatement than food-reinforced behaviors (56). Still, stress is associated with increased consumption of palatable foods and weight gain and a potentiated OFC activation to food rewards (57).

It appears as if DA activation of the striatum by cues (including drug-related contexts) is involved with the desire (wanting), as the trigger of behaviors geared toward consuming the desired reward. Indeed, DA also modulates motivation and persistence (58). Because drug taking becomes the main motivational drive in addiction, addicted subjects are aroused and motivated by the process of obtaining the drug but withdrawn and apathetic when exposed to non-drug-related activities. This shift has been studied by comparing brain activation in the presence or absence of drug cues. In contrast to the decreases in prefrontal activity reported in detoxified cocaine abusers when not stimulated with drug or drug cues [see review (59)], ventral and medial prefrontal regions (including OFC and ventral ACC) become activated with exposure to craving-inducing stimuli (either drugs or cues) $(60,61)$. Also, when cocaine-addicted subjects purposefully inhibited craving when exposed to drug cues, those who were successful decreased metabolism in medial OFC (processes motivational value of a reinforcer) and NAc (predicts reward) (55), consistent with the involvement of OFC, ACC, and striatum in the enhanced motivation to procure the drug seen in addiction. The OFC is 
similarly involved in attributing salience value to food (62), helping to assess its expected pleasantness and palatability as a function of its context. Normal-weight subjects exposed to food cues showed increased activity in OFC, which was associated with food craving (63). There is evidence that the OFC also supports conditioned cue-elicited feeding (64) and that it contributes to overeating, irrespective of hunger signals (65). Indeed, several lines of research support a functional link between OFC impairment and disordered eating, including the reported association between disinhibited eating in obese adolescents and reduced OFC volume (66). In contrast, greater volumes of the medial OFC were seen in both bulimia nervosa and binge-eating disorder patients (67), and damage to the OFC in rhesus monkeys has been reported to result in hyperphagia (68).

The emergence of cue-conditioned cravings and incentive motivation for the reward, which for food also occur in healthy individuals who do not overeat (69), would not be as devastating were they not coupled with growing deficits in the brain's ability to inhibit maladaptive behaviors.

\section{Self-Control and the Ability to Resist Temptation}

The capacity to inhibit prepotent responses and exert self-control contributes to an individual's ability to suppress inappropriate behaviors, such as taking drugs or eating past the point of satiety, thus modulating the vulnerability to addiction or obesity, respectively $(70,71)$. Preclinical and clinical studies have suggested that impairments in striatal DA signaling may undermine self-control as described below.

Imaging studies revealed that reduced availability of striatal D2R receptors is a consistent abnormality across a wide variety of drug addictions and one that can persist months after detoxification [reviewed in (59)]. Similarly, preclinical studies have shown that repeated drug exposures are associated with long-lasting reductions in striatal D2R levels and signaling (72,73). In the striatum, D2 receptors mediate signaling through the indirect pathway that modulates frontocortical regions, and its down-regulation enhances drug sensitization in animal models (74), whereas its upregulation interferes with drug consumption (75). Moreover, inhibition of striatal D2R or activation of D1 receptorexpressing striatal neurons (mediate signaling in the striatal direct pathway) enhances the sensitivity to drug rewards (74). Dysregulation of striatal D2R signaling has also been implicated in obesity $(76,77)$ and in compulsive food intake in obese rodents $(78)$. However, the extent to which there are similar opposite regulatory processes for the direct (decreased) and indirect (increased) pathways in obesity remains unclear.

The reduction in striatal D2R in addiction and in obesity is associated with decreased activity in prefrontal regions involved in salience attribution (OFC), error detection and inhibition (ACC), and decision making (dorsolateral prefrontal cortex) $(73,79,80)$. Thus, improper regulation by D2R-mediated DA signaling of these frontal regions in addicted and obese subjects could underlie the enhanced incentive motivational value of drugs or food and the difficulty in resisting them (70,71). In addition, because impairments in OFC and ACC are associated with compulsive behaviors and impulsivity, impaired modulation of dopamine in these regions is likely to contribute to the compulsive and impulsive patterns of drug (addiction) or food (obesity) intake. 
Similarly, a pre-existing dysfunction of prefrontal regions could also underlie the vulnerability for excessive drug or food consumption, which would be further exacerbated by decreases in striatal D2R (either drug- or stress-induced; it is unclear whether obesogenic diets decrease striatal D2R). Indeed, we showed that subjects who, despite having a high genetic risk for alcoholism (positive family history of alcoholism) were not alcoholics, had higher than normal striatal D2R, which was associated with normal prefrontal metabolism (81) that might have protected them from alcoholism. Interestingly, a recent study of siblings discordant for their addiction to stimulant drugs found that the OFC of the addicted siblings was significantly smaller than that of nonaddicted siblings or control subjects (82).

Brain imaging data also support the notion that structural and functional changes in brain regions implicated in executive (including inhibitory) function are associated with high BMI in otherwise healthy individuals. For example, a magnetic resonance imaging study of elderly women found a negative correlation between BMI and gray matter volumes (including frontal regions), which, in the OFC, correlated with impaired executive function (83). Other studies found significant decreases in blood flow in the prefrontal cortex associated with higher weight in healthy control subjects $(84,85)$, and a functional magnetic resonance imaging study reported impaired executive function in obese women (86). Similarly, in healthy control subjects, BMI was negatively correlated with metabolic activity in prefrontal regions for which the activity predicted the scores on tests of executive function (87). Interestingly, successful dieters activate prefrontal regions involved in inhibitory control (dorsolateral prefrontal cortex and OFC) while eating (88). These and other studies evince a correlation between executive function and addiction and obesity risk/phenotypes, and further research will help clarify details as well as differences between these phenotypes.

Clearly, individual differences in executive function can constitute a prodromal risk for later obesity in some individuals (89). Interestingly, a cross-sectional investigation of children's ability to self-regulate, solve problems, and engage in goal-directed health behaviors revealed executive function proficiency to be negatively correlated not only with substance use but also with the consumption of high-calorie snack foods and with sedentary behaviors (90).

\section{Awareness of Interoceptive Signals}

The middle insula plays a critical role in cravings for food, cocaine, and cigarettes (91-93). Its importance in addiction was highlighted when a study found that smokers who suffered a stroke that damaged the insula were able to quit easily and without experiencing either cravings or relapse (94). The insula, particularly its more anterior regions, is reciprocally connected to several limbic regions and supports interoceptive functions, integrating the autonomic and visceral information with emotion and motivation and providing conscious awareness of these urges (95). Consistent with this hypothesis, many imaging studies show differential activation of the insula during craving (95). Accordingly, the reactivity of the insula has been suggested as a biomarker to help predict relapse (96).

The insula is also a primary gustatory area, which participates in many aspects of eating behaviors, such as taste. In addition, the rostral insula (connected to primary taste cortex) 
provides information to the OFC that influences its multimodal representation of the pleasantness or reward value of incoming food (97). Because of the insula's involvement in the interoceptive sense of the body, in emotional awareness (98), and in motivation and emotion (97), a contribution of insular impairment in obesity should not be surprising. Indeed, gastric distention results in activation of the posterior insula, a likely reflection of its role in the awareness of body states (in this case of fullness) (99). Moreover, in lean but not in obese subjects, gastric distention resulted in activation of the amygdala and deactivation of the anterior insula (100). The lack of amygdalar response in obese subjects could reflect a blunted interoceptive awareness of bodily states linked with satiety (full stomach). Even though the modulation of insular activity by DA has been poorly investigated, it is recognized that DA is involved in responses to the tasting of palatable foods that are mediated through the insula (101). Indeed, in humans, tasting palatable foods activated the insula and midbrain areas $(102,103)$. In addition, DA signaling appears to also be necessary for sensing the calorie content of food. For example, when normal weight women tasted a sweetener with calories (sucrose), both the insula and DA midbrain areas became activated, whereas tasting a calorie-free sweetener (sucralose) only activated the insula (103). Obese subjects exhibit greater insular activation than normal control subjects when tasting a liquid meal with sugar and fat (102). In contrast, subjects who have recovered from anorexia nervosa show less insular activation when tasting sucrose and no association of feelings of pleasantness with insular activation as observed in control subjects (104).

\section{Dark Side of the Addictive Dimension}

The dark side of addiction was initially proposed by Koob and Le Moal (105) to describe the transition that drug-addicted individuals experience between the initial, pleasurable use of drugs to the one that, with repeated use, results in drug consumption to relieve negative emotional states. More recently, Parylak et al. (106) have proposed that a similar transition may occur in food addiction with exposure to obesogenic foods. They pointed out that both in drug addiction and in certain instances of obesity or eating disorders, stress and negative moods (depression, anxiety) can trigger compulsive drug (in addiction) or food intake in humans (obesity and eating disorders). Their model highlights the importance of brain circuits that modulate stress reactivity and antireward, which are enhanced after repeated drug exposures but also after intermittent access to palatable foods. Central to their model is an enhanced sensitivity of the extended amygdala and increased signaling through corticotropin-releasing factor and corticotropin-releasing factor related peptides, which mediate responses to stress.

In parallel, the recognition that the habenula mediates inhibition of VTA DA neuron firing when an expected reward does not materialize (107) also implicates this region in contributing to such antireward circuitry. Thus, an enhanced sensitivity of the habenula, as a result of chronic drug exposure, could underlie a greater reactivity to drug cues and also contribute to dysphoric states during withdrawal. Indeed, activation of the lateral habenula, in animal models of cocaine or heroin addiction, has been associated with relapse $(108,109)$. The habenula is also implicated in food reward: neurons in the rostromedial tegmental nucleus, which receive a major input from the lateral habenula, project to VTA DA neurons and are activated after food deprivation (110). These findings are consistent with a role for 
the lateral habenula in mediating responses to aversive stimuli or states such as those that occur during dieting or drug withdrawal.

\section{Summary and Implications}

The human brain is a complex biological system that is organized in the layered architecture of interactive networks, sometimes called bowtie (111), whereby a narrowing funnel of many potential inputs converges onto a relatively small number of processes before fanning out again into a diversity of outputs. Eating behaviors present a great example of this architecture where the hypothalamus is a central knot of the metabolic bowtie (Figure 2A) and midbrain DA nuclei (VTA and substantia nigra) and their projection regions (NAc; amygdala; hippocampus; dorsal striatum; and prefrontal, motor, and temporal cortices) represent a central knot for a system that reacts to salient external stimuli (including drugs and food), as well as relevant internal signals (i.e., hunger, thirst) (Figure 2B). These two systems can be viewed as examples of nested layered architectures (111), in which the DA bowtie subserves the internal signals mediated by hypothalamic signaling (Figure 2C). This model helps explain the proliferating examples of contact points between obesity and addiction, some of which were highlighted in this review.

Thus, strategies that borrow from successful prevention and treatment strategies in addiction might be beneficial in obesity. Future research in this area should include social and policy strategies to decrease the availability of obesogenic food (restricting its sales, increasing their costs), increase access to alternative reinforcers (healthy food that can compete in price for high-calorie food and access to physical activity), and develop education (taking advantage of schools, families, and communities). Similarly, treatment research could focus on clinical and social strategies to decrease the reinforcing properties of food and reestablish/enhance the rewarding properties of alternative reinforcers (incorporate social rewards, physical activity, contingencies), inhibit conditioned learned associations (extinguishing conditioned responses, learning new associations), decrease stress reactivity and improve mood (physical activity, cognitive therapy), and strengthen general purpose self-control (cognitive and behavioral treatments). The translational aspects that emerge from recognizing the overlapping nature of these diseases represent just one of several possible future research directions identified in this review (Table 1).

It is telling that the two largest preventable threats to public health (smoking and obesity) involve the reward circuit that drives the motivation of individuals to consume rewards despite the fact that they are harmful to their health. Solutions to both of these epidemics will require, in addition to individual tailored approaches, broad public health initiatives that promote smart changes in the environment.

\section{Acknowledgments}

This research was supported by the National Institutes of Health (Intramural Research Program of the National Institute on Alcoholism and Alcohol Abuse). 


\section{References}

1. Naukkarinen J, Surakka I, Pietilainen KH, Rissanen A, Salomaa V, Ripatti S, et al. Use of genomewide expression data to mine the "Gray Zone" of GWA studies leads to novel candidate obesity genes. PLoS Genet. 2010; 6:e1000976. [PubMed: 20532202]

2. Speliotes EK, Willer CJ, Berndt SI, Monda KL, Thorleifsson G, Jackson AU, et al. Association analyses of 249,796 individuals reveal 18 new loci associated with body mass index. Nat Genet. 2010; 42:937-948. [PubMed: 20935630]

3. de Krom M, Bauer F, Collier D, Adan RA, la Fleur SE. Genetic variation and effects on human eating behavior. Annu Rev Nutr. 2009; 29:283-304. [PubMed: 19400703]

4. Blum K, Braverman ER, Wood RC, Gill J, Li C, Chen TJ, et al. Increased prevalence of the Taq I A1 allele of the dopamine receptor gene (DRD2) in obesity with comorbid substance use disorder: A preliminary report. Pharmacogenetics. 1996; 6:297-305. [PubMed: 8873216]

5. Schleinitz D, Carmienke S, Bottcher Y, Tonjes A, Berndt J, Kloting N, et al. Role of genetic variation in the cannabinoid type 1 receptor gene (CNR1) in the pathophysiology of human obesity. Pharmacogenomics. 2010; 11:693-702. [PubMed: 20415562]

6. Benyamina A, Kebir O, Blecha L, Reynaud M, Krebs MO. CNR1 gene polymorphisms in addictive disorders: A systematic review and a meta-analysis. Addict Biol. 2010; 16:1-6. [PubMed: 20192949]

7. Davis CA, Levitan RD, Reid C, Carter JC, Kaplan AS, Patte KA, et al. Dopamine for "wanting" and opioids for "liking": A comparison of obese adults with and without binge eating. Obesity (Silver Spring). 2009; 17:1220-1225. [PubMed: 19282821]

8. Ray LA, Barr CS, Blendy JA, Oslin D, Goldman D, Anton RF. The role of the Asn40Asp polymorphism of the mu opioid receptor gene (OPRM1) on alcoholism etiology and treatment: A critical review. Alcohol Clin Exp Res. 2011; 36:385-394. [PubMed: 21895723]

9. Volkow ND, Wang GJ, Tomasi D, Baler RD. Obesity and addiction: Neurobiological overlaps. Obes Rev. 2013; 14:2-18. [PubMed: 23016694]

10. Opland DM, Leinninger GM, Myers MG Jr. Modulation of the mesolimbic dopamine system by leptin. Brain Res. 2011; 1350:65-70. [PubMed: 20417193]

11. Alhadeff AL, Rupprecht LE, Hayes MR. GLP-1 neurons in the nucleus of the solitary tract project directly to the ventral tegmental area and nucleus accumbens to control for food intake. Endocrinology. 2012; 153:647-658. [PubMed: 22128031]

12. Rinaman L. Ascending projections from the caudal visceral nucleus of the solitary tract to brain regions involved in food intake and energy expenditure. Brain Res. 2010; 1350:18-34. [PubMed: 20353764]

13. Abizaid A, Liu ZW, Andrews ZB, Shanabrough M, Borok E, Elsworth JD, et al. Ghrelin modulates the activity and synaptic input organization of midbrain dopamine neurons while promoting appetite. J Clin Invest. 2006; 116:3229-3239. [PubMed: 17060947]

14. Jerlhag E, Egecioglu E, Dickson SL, Douhan A, Svensson L, Engel JA. Ghrelin administration into tegmental areas stimulates locomotor activity and increases extracellular concentration of dopamine in the nucleus accumbens. Addict Biol. 2007; 12:6-16. [PubMed: 17407492]

15. Figlewicz D, Evans SB, Murphy J, Hoen M, Baskin DG. Expression of receptors for insulin and leptin in the ventral tegmental area/substantia nigra (VTA/SN) of the rat. Brain Res. 2003; 964:107-115. [PubMed: 12573518]

16. Leshan R, Opland DM, Louis GW, Leinninger GM, Patterson CM, Rhodes CJ, et al. Ventral tegmental area leptin receptor neurons specifically project to and regulate cocaine- and amphetamine-regulated transcript neurons of the extended central amygdala. J Neurosci. 2010; 30:5713-5723. [PubMed: 20410123]

17. Figlewicz D, Bennett JL, Aliakbari S, Zavosh A, Sipols AJ. Insulin acts at different CNS sites to decrease acute sucrose intake and sucrose self-administration in rats. Am J Physiol Regul Integr Comp Physiol. 2008; 295:R388-R394. [PubMed: 18525010]

18. Fadel J, Deutch AY. Anatomical substrates of orexindopamine interactions: Lateral hypothalamic projections to the ventral tegmental area. Neuroscience. 2002; 111:379-387. [PubMed: 11983323] 
19. Davis JF, Choi DL, Shurdak JD, Krause EG, Fitzgerald MF, Lipton JW, et al. Central melanocortins modulate mesocorticolimbic activity and food seeking behavior in the rat. Physiol Behav. 2011; 102:491-495. [PubMed: 21172367]

20. Davis JF, Tracy AL, Schurdak JD, Tschop MH, Lipton JW, Clegg DJ, Benoit SC. Exposure to elevated levels of dietary fat attenuates psychostimulant reward and mesolimbic dopamine turnover in the rat. Behav Neurosci. 2008; 122:1257-1263. [PubMed: 19045945]

21. Bluml V, Kapusta N, Vyssoki B, Kogoj D, Walter H, Lesch OM. Relationship between substance use and body mass index in young males. Am J Addict. 2012; 21:72-77. [PubMed: 22211349]

22. Simon G, Von Korff M, Saunders K, Miglioretti DL, Crane PK, van Belle G, Kessler RC. Association between obesity and psychiatric disorders in the US adult population. Arch Gen Psychiatry. 2006; 63:824-830. [PubMed: 16818872]

23. Blendy JA, Strasser A, Walters CL, Perkins KA, Patterson F, Berkowitz R, Lerman C. Reduced nicotine reward in obesity: Cross-comparison in human and mouse. Psychopharmacology (Berl). 2005; 180:306-315. [PubMed: 15719224]

24. Warren M, Frost-Pineda K, Gold M. Body mass index and marijuana use. J Addict Dis. 2005; 24:95-100. [PubMed: 16186086]

25. Davis JF, Choi DL, Benoit SC. Insulin, leptin and reward. Trends Endocrinol Metab. 2010; 21:6874. [PubMed: 19818643]

26. Suzuki J, Haimovici F, Chang G. Alcohol use disorders after bariatric surgery. Obes Surg. 2012; 22:201-207. [PubMed: 21188544]

27. Volkow ND, O'Brien CP. Issues for DSM-V: Should obesity be included as a brain disorder? Am J Psychiatry. 2007; 164:708-710. [PubMed: 17475727]

28. Palmiter RD. Dopamine signaling in the dorsal striatum is essential for motivated behaviors: Lessons from dopamine-deficient mice. Ann N Y Acad Sci. 2008; 1129:35-46. [PubMed: 18591467]

29. Moore, K.; Lookingland, K. Dopaminergic neuronal systems in the hypothalamus. In: Bloom, FE.; Kupfer, DJ., editors. Psychopharmacology-The Fourth Generation of Progress. New York: Raven Press; 2000.

30. Gudelsky GA, Passaro E, Meltzer HY. Delayed activation of tuberoinfundibular dopamine neurons and suppression of prolactin secretion in the rat after morphine administration. J Pharmacol Exp Ther. 1986; 236:641-645. [PubMed: 3950867]

31. Geisler S, Wise RA. Functional implications of glutamatergic projections to the ventral tegmental area. Rev Neurosci. 2008; 19:227-244. [PubMed: 19145985]

32. Norgren R, Hajnal A, Mungarndee SS. Gustatory reward and the nucleus accumbens. Physiol Behav. 2006; 89:531-535. [PubMed: 16822531]

33. Schultz W. Predictive reward signal of dopamine neurons. J Neurophysiol. 1998; 80:1-27. [PubMed: 9658025]

34. Nair SG, Adams-Deutsch T, Epstein DH, Shaham Y. The neuropharmacology of relapse to food seeking: Methodology, main findings, and comparison with relapse to drug seeking. Prog Neurobiol. 2009; 89:18-45. [PubMed: 19497349]

35. Kauer JA, Malenka RC. Synaptic plasticity and addiction. Nat Rev Neurosci. 2007; 8:844-858. [PubMed: 17948030]

36. Luo Z, Volkow ND, Heintz N, Pan Y, Du C. Acute cocaine induces fast activation of D1 receptor and progressive deactivation of $\mathrm{D} 2$ receptor striatal neurons: In vivo optical microprobe [Ca2+]i imaging. J Neurosci. 2011; 31:13180-13190. [PubMed: 21917801]

37. Ball KT, Combs TA, Beyer DN. Opposing roles for dopamine D1- and D2-like receptors in discrete cue-induced reinstatement of food seeking. Behav Brain Res. 2011; 222:390-393. [PubMed: 21497172]

38. Everitt BJ, Belin D, Economidou D, Pelloux Y, Dalley JW, Robbins TW. Review. Neural mechanisms underlying the vulnerability to develop compulsive drug-seeking habits and addiction. Philos Trans R Soc Lond B Biol Sci. 2008; 363:3125-3135. [PubMed: 18640910]

39. Volkow ND, Wang GJ, Fowler JS, Tomasi D, Telang F, Baler R. Addiction: Decreased reward sensitivity and increased expectation sensitivity conspire to overwhelm the brain's control circuit. Bioessays. 2010; 32:748-755. [PubMed: 20730946] 
40. Lenoir M, Serre F, Cantin L, Ahmed SH. Intense sweetness surpasses cocaine reward. PLoS One. 2007; 2:e698. [PubMed: 17668074]

41. Avena NM, Rada P, Hoebel BG. Evidence for sugar addiction: Behavioral and neurochemical effects of intermittent, excessive sugar intake. Neurosci Biobehav Rev. 2008; 32:20-39. [PubMed: 17617461]

42. Small DM, Jones-Gotman M, Dagher A. Feeding-induced dopamine release in dorsal striatum correlates with meal pleasantness ratings in healthy human volunteers. Neuroimage. 2003; 19:1709-1715. [PubMed: 12948725]

43. Volkow ND, Wang GJ, Fowler JS, Telang F. Overlapping neuronal circuits in addiction and obesity: Evidence of systems pathology. Philos Trans R Soc Lond B Biol Sci. 2008; 363:31913200. [PubMed: 18640912]

44. Volkow ND, Wang GJ, Baler RD. Reward, dopamine and the control of food intake: Implications for obesity. Trends Cogn Sci. 2011; 15:37-46. [PubMed: 21109477]

45. Stice E, Spoor S, Bohon C, Veldhuizen MG, Small DM. Relation of reward from food intake and anticipated food intake to obesity: A functional magnetic resonance imaging study. J Abnorm Psychol. 2008; 117:924-935. [PubMed: 19025237]

46. Stice E, Spoor S, Bohon C, Small DM. Relation between obesity and blunted striatal response to food is moderated by TaqIA A1 allele. Science. 2008; 322:449-452. [PubMed: 18927395]

47. Stoeckel LE, Weller RE, Cook EW 3rd, Twieg DB, Knowlton RC, Cox JE. Widespread rewardsystem activation in obese women in response to pictures of high-calorie foods. Neuroimage. 2008; 41:636-647. [PubMed: 18413289]

48. Volkow ND, Wang GJ, Telang F, Fowler JS, Logan J, Childress AR, et al. Cocaine cues and dopamine in dorsal striatum: Mechanism of craving in cocaine addiction. J Neurosci. 2006; 26:6583-6588. [PubMed: 16775146]

49. Vanderschuren LJ, Di Ciano P, Everitt BJ. Involvement of the dorsal striatum in cue-controlled cocaine seeking. J Neurosci. 2005; 25:8665-8670. [PubMed: 16177034]

50. Killgore WD, Yurgelun-Todd DA. Body mass predicts orbitofrontal activity during visual presentations of high-calorie foods. Neuroreport. 2005; 16:859-863. [PubMed: 15891585]

51. Wang GJ, Geliebter A, Volkow ND, Telang FW, Logan J, Jayne MC, et al. Enhanced striatal dopamine release during food stimulation in binge eating disorder. Obesity (Silver Spring). 2011; 19:1601-1608. [PubMed: 21350434]

52. Petrovich GD. Forebrain circuits and control of feeding by learned cues. Neurobiol Learn Mem. 2010; 95:152-158. [PubMed: 20965265]

53. Lasseter HC, Wells AM, Xie X, Fuchs RA. Interaction of the basolateral amygdala and orbitofrontal cortex is critical for drug context-induced reinstatement of cocaine-seeking behavior in rats. Neuropsychopharmacology. 2011; 36:711-720. [PubMed: 21124303]

54. Wang GJ, Volkow ND, Telang F, Jayne M, Ma Y, Pradhan K, et al. Evidence of gender differences in the ability to inhibit brain activation elicited by food stimulation. Proc Natl Acad Sci U S A. 2009; 106:1249-1254. [PubMed: 19164587]

55. Volkow ND, Fowler JS, Wang GJ, Telang F, Logan J, Jayne M, et al. Cognitive control of drug craving inhibits brain reward regions in cocaine abusers. Neuroimage. 2009; 49:2536-2543. [PubMed: 19913102]

56. Kearns DN, Gomez-Serrano MA, Tunstall BJ. A review of preclinical research demonstrating that drug and non-drug reinforcers differentially affect behavior. Curr Drug Abuse Rev. 2011; 4:261269. [PubMed: 21999697]

57. Rudenga KJ, Sinha R, Small DM. Acute stress potentiates brain response to milkshake as a function of body weight and chronic stress [published online ahead of print March 20]. Int J Obes (Lond). 2012

58. Salamone JD, Correa M, Farrar A, Mingote SM. Effort-related functions of nucleus accumbens dopamine and associated forebrain circuits. Psychopharmacology (Berl). 2007; 191:461-482. [PubMed: 17225164]

59. Volkow ND, Fowler JS, Wang GJ, Baler R, Telang F. Imaging dopamine's role in drug abuse and addiction. Neuropharmacology. 2009; 56(suppl 1):3-8. [PubMed: 18617195] 
60. Grant S, London ED, Newlin DB, Villemagne VL, Liu X, Contoreggi C, et al. Activation of memory circuits during cue-elicited cocaine craving. Proc Natl Acad Sci U S A. 1996; 93:1204012045. [PubMed: 8876259]

61. Wang GJ, Volkow ND, Fowler JS, Cervany P, Hitzemann RJ, Pappas NR, et al. Regional brain metabolic activation during craving elicited by recall of previous drug experiences. Life Sci. 1999; 64:775-784. [PubMed: 10075110]

62. Grabenhorst F, Rolls ET, Bilderbeck A. How cognition modulates affective responses to taste and flavor: Top-down influences on the orbitofrontal and pregenual cingulate cortices. Cereb Cortex. 2008; 18:1549-1559. [PubMed: 18056086]

63. Wang GJ, Volkow ND, Telang F, Jayne M, Ma J, Rao M, et al. Exposure to appetitive food stimuli markedly activates the human brain. Neuroimage. 2004; 21:1790-1797. [PubMed: 15050599]

64. Holland PC, Petrovich GD. A neural systems analysis of the potentiation of feeding by conditioned stimuli. Physiol Behav. 2005; 86:747-761. [PubMed: 16256152]

65. Ogden J, Wardle J. Cognitive restraint and sensitivity to cues for hunger and satiety. Physiol Behav. 1990; 47:477-481. [PubMed: 2359756]

66. Maayan L, Hoogendoorn C, Sweat V, Convit A. Disinhibited eating in obese adolescents is associated with orbitofrontal volume reductions and executive dysfunction. Obesity (Silver Spring). 2011; 19:1382-1387. [PubMed: 21350433]

67. Schafer A, Vaitl D, Schienle A. Regional grey matter volume abnormalities in bulimia nervosa and binge-eating disorder. Neuroimage. 2010; 50:639-643. [PubMed: 20035881]

68. Machado CJ, Bachevalier J. Measuring reward assessment in a semi-naturalistic context: The effects of selective amygdala, orbital frontal or hippocampal lesions. Neuroscience. 2007; 148:599-611. [PubMed: 17693034]

69. Volkow ND, Wang GJ, Fowler JS, Logan J, Jayne M, Franceschi D, et al. "Nonhedonic” food motivation in humans involves dopamine in the dorsal striatum and methylphenidate amplifies this effect. Synapse. 2002; 44:175-180. [PubMed: 11954049]

70. Volkow ND, Fowler JS. Addiction, a disease of compulsion and drive: Involvement of the orbitofrontal cortex. Cereb Cortex. 2000; 10:318-325. [PubMed: 10731226]

71. Volkow ND, Wang GJ, Telang F, Fowler JS, Thanos PK, Logan J, et al. Low dopamine striatal D2 receptors are associated with prefrontal metabolism in obese subjects: Possible contributing factors. Neuroimage. 2008; 42:1537-1543. [PubMed: 18598772]

72. Nader MA, Morgan D, Gage HD, Nader SH, Calhoun TL, Buchheimer N, et al. PET imaging of dopamine D2 receptors during chronic cocaine self-administration in monkeys. Nat Neurosci. 2006; 9:1050-1056. [PubMed: 16829955]

73. Volkow ND, Chang L, Wang GJ, Fowler JS, Ding YS, Sedler M, et al. Low level of brain dopamine D2 receptors in methamphetamine abusers: Association with metabolism in the orbitofrontal cortex. Am J Psychiatry. 2001; 158:2015-2021. [PubMed: 11729018]

74. Ferguson SM, Eskenazi D, Ishikawa M, Wanat MJ, Phillips PE, Dong Y, et al. Transient neuronal inhibition reveals opposing roles of indirect and direct pathways in sensitization. Nat Neurosci. 2011; 14:22-24. [PubMed: 21131952]

75. Thanos PK, Michaelides M, Umegaki H, Volkow ND. D2R DNA transfer into the nucleus accumbens attenuates cocaine self-administration in rats. Synapse. 2008; 62:481-486. [PubMed: 18418874]

76. de Weijer BA, van de Giessen E, van Amelsvoort TA, Boot E, Braak B, Janssen IM, et al. Lower striatal dopamine $\mathrm{D} 2 / 3$ receptor availability in obese compared with non-obese subjects. EJNMMI Res. 2011; 1:37. [PubMed: 22214469]

77. Geiger BM, Haburcak M, Avena NM, Moyer MC, Hoebel BG, Pothos EN. Deficits of mesolimbic dopamine neurotransmission in rat dietary obesity. Neuroscience. 2009; 159:1193-1199. [PubMed: 19409204]

78. Johnson PM, Kenny PJ. Dopamine D2 receptors in addiction-like reward dysfunction and compulsive eating in obese rats. Nat Neurosci. 2010; 13:635-641. [PubMed: 20348917]

79. Volkow ND, Fowler JS, Wang GJ, Hitzemann R, Logan J, Schlyer DJ, et al. Decreased dopamine D2 receptor availability is associated with reduced frontal metabolism in cocaine abusers. Synapse. 1993; 14:169-177. [PubMed: 8101394] 
80. Volkow ND, Wang GJ, Telang F, Fowler JS, Logan J, Jayne M, et al. Profound decreases in dopamine release in striatum in detoxified alcoholics: Possible orbitofrontal involvement. J Neurosci. 2007; 27:12700-12706. [PubMed: 18003850]

81. Volkow ND, Wang GJ, Begleiter H, Porjesz B, Fowler JS, Telang F, et al. High levels of dopamine D2 receptors in unaffected members of alcoholic families: Possible protective factors. Arch Gen Psychiatry. 2006; 63:999-1008. [PubMed: 16953002]

82. Ersche KD, Jones PS, Williams GB, Turton AJ, Robbins TW, Bullmore ET. Abnormal brain structure implicated in stimulant drug addiction. Science. 2012; 335:601-604. [PubMed: 22301321]

83. Walther K, Birdsill AC, Glisky EL, Ryan L. Structural brain differences and cognitive functioning related to body mass index in older females. Hum Brain Mapp. 2010; 31:1052-1064. [PubMed: 19998366]

84. Willeumier K, Taylor DV, Amen DG. Elevated body mass in National Football League players linked to cognitive impairment and decreased prefrontal cortex and temporal pole activity. Transl Psychiatry. 2012; 2:e68. [PubMed: 22832730]

85. Willeumier KC, Taylor DV, Amen DG. Elevated BMI is associated with decreased blood flow in the prefrontal cortex using SPECT imaging in healthy adults. Obesity (Silver Spring). 2011; 19:1095-1097. [PubMed: 21311507]

86. Kishinevsky FI, Cox JE, Murdaugh DL, Stoeckel LE, Cook EW 3rd, Weller RE. fMRI reactivity on a delay discounting task predicts weight gain in obese women. Appetite. 2012; 58:582-592. [PubMed: 22166676]

87. Volkow ND, Wang GJ, Telang F, Fowler JS, Goldstein RZ, Alia-Klein N, et al. Inverse association between BMI and prefrontal metabolic activity in healthy adults. Obesity (Silver Spring). 2009; 17:60-65. [PubMed: 18948965]

88. DelParigi A, Chen K, Salbe AD, Hill JO, Wing RR, Reiman EM, Tataranni PA. Successful dieters have increased neural activity in cortical areas involved in the control of behavior. Int J Obes (Lond). 2007; 31:440-448. [PubMed: 16819526]

89. Riggs NR, Huh J, Chou CP, Spruijt-Metz D, Pentz MA. Executive function and latent classes of childhood obesity risk. J Behav Med. 2012; 6:642-650. [PubMed: 22218938]

90. Riggs NR, Spruijt-Metz D, Chou CP, Pentz MA. Relationships between executive cognitive function and lifetime substance use and obesity-related behaviors in fourth grade youth. Child Neuropsychol. 2012; 18:1-11. [PubMed: 21480013]

91. Bonson KR, Grant SJ, Contoreggi CS, Links JM, Metcalfe J, Weyl HL, et al. Neural systems and cue-induced cocaine craving. Neuropsychopharmacology. 2002; 26:376-386. [PubMed: 11850152]

92. Pelchat ML, Johnson A, Chan R, Valdez J, Ragland JD. Images of desire: Food-craving activation during fMRI. Neuroimage. 2004; 23:1486-1493. [PubMed: 15589112]

93. Wang Z, Faith M, Patterson F, Tang K, Kerrin K, Wileyto EP, et al. Neural substrates of abstinenceinduced cigarette cravings in chronic smokers. J Neurosci. 2007; 27:14035-14040. [PubMed: 18094242]

94. Naqvi NH, Rudrauf D, Damasio H, Bechara A. Damage to the insula disrupts addiction to cigarette smoking. Science. 2007; 315:531-534. [PubMed: 17255515]

95. Naqvi NH, Bechara A. The hidden island of addiction: The insula. Trends Neurosci. 2009; 32:5667. [PubMed: 18986715]

96. Janes AC, Pizzagalli DA, Richardt S, deB Frederick B, Chuzi S, Pachas G, et al. Brain reactivity to smoking cues prior to smoking cessation predicts ability to maintain tobacco abstinence. Biol Psychiatry. 2010; 67:722-729. [PubMed: 20172508]

97. Rolls ET. Functions of the orbitofrontal and pregenual cingulate cortex in taste, olfaction, appetite and emotion. Acta Physiol Hung. 2008; 95:131-164. [PubMed: 18642756]

98. Craig AD. Interoception: The sense of the physiological condition of the body. Curr Opin Neurobiol. 2003; 13:500-505. [PubMed: 12965300]

99. Wang GJ, Tomasi D, Backus W, Wang R, Telang F, Geliebter A, et al. Gastric distention activates satiety circuitry in the human brain. Neuroimage. 2008; 39:1824-1831. [PubMed: 18155924] 
100. Tomasi D, Wang GJ, Wang R, Backus W, Geliebter A, Telang F, et al. Association of body mass and brain activation during gastric distention: Implications for obesity. PLoS One. 2009; 4:e6847. [PubMed: 19718256]

101. Hajnal A, Norgren R. Taste pathways that mediate accumbens dopamine release by sapid sucrose. Physiol Behav. 2005; 84:363-369. [PubMed: 15763573]

102. DelParigi A, Chen K, Salbe AD, Reiman EM, Tataranni PA. Sensory experience of food and obesity: A positron emission tomography study of the brain regions affected by tasting a liquid meal after a prolonged fast. Neuroimage. 2005; 24:436-443. [PubMed: 15627585]

103. Frank GK, Oberndorfer TA, Simmons AN, Paulus MP, Fudge JL, Yang TT, Kaye WH. Sucrose activates human taste pathways differently from artificial sweetener. Neuroimage. 2008; 39:1559-1569. [PubMed: 18096409]

104. Wagner A, Aizenstein H, Mazurkewicz L, Fudge J, Frank GK, Putnam K, et al. Altered insula response to taste stimuli in individuals recovered from restricting-type anorexia nervosa. Neuropsychopharmacology. 2008; 33:513-523. [PubMed: 17487228]

105. Koob GF, Le Moal M. Plasticity of reward neurocircuitry and the 'dark side' of drug addiction. Nat Neurosci. 2005; 8:1442-1444. [PubMed: 16251985]

106. Parylak SL, Koob GF, Zorrilla EP. The dark side of food addiction. Physiol Behav. 2011; 104:149-156. [PubMed: 21557958]

107. Kimura M, Satoh T, Matsumoto N. What does the habenula tell dopamine neurons? Nat Neurosci. 2007; 10:677-678. [PubMed: 17525761]

108. Zhang F, Zhou W, Liu H, Zhu H, Tang S, Lai M, Yang G. Increased c-Fos expression in the medial part of the lateral habenula during cue-evoked heroin-seeking in rats. Neurosci Lett. 2005; 386:133-137. [PubMed: 16002220]

109. Brown RM, Short JL, Lawrence AJ. Identification of brain nuclei implicated in cocaine-primed reinstatement of conditioned place preference: A behaviour dissociable from sensitization. PLoS One. 2011; 5:e15889. [PubMed: 21209913]

110. Jhou TC, Fields HL, Baxter MG, Saper CB, Holland PC. The rostromedial tegmental nucleus (RMTg), a GABAergic afferent to midbrain dopamine neurons, encodes aversive stimuli and inhibits motor responses. Neuron. 2009; 61:786-800. [PubMed: 19285474]

111. Csete M, Doyle J. Bow ties, metabolism and disease. Trends Biotechnol. 2004; 22:446-450. [PubMed: 15331224]

112. Haber SN, Fudge JL, McFarland NR. Striatonigrostriatal pathways in primates form an ascending spiral from the shell to the dorsolateral striatum. J Neurosci. 2000; 20:2369-2382. [PubMed: 10704511] 


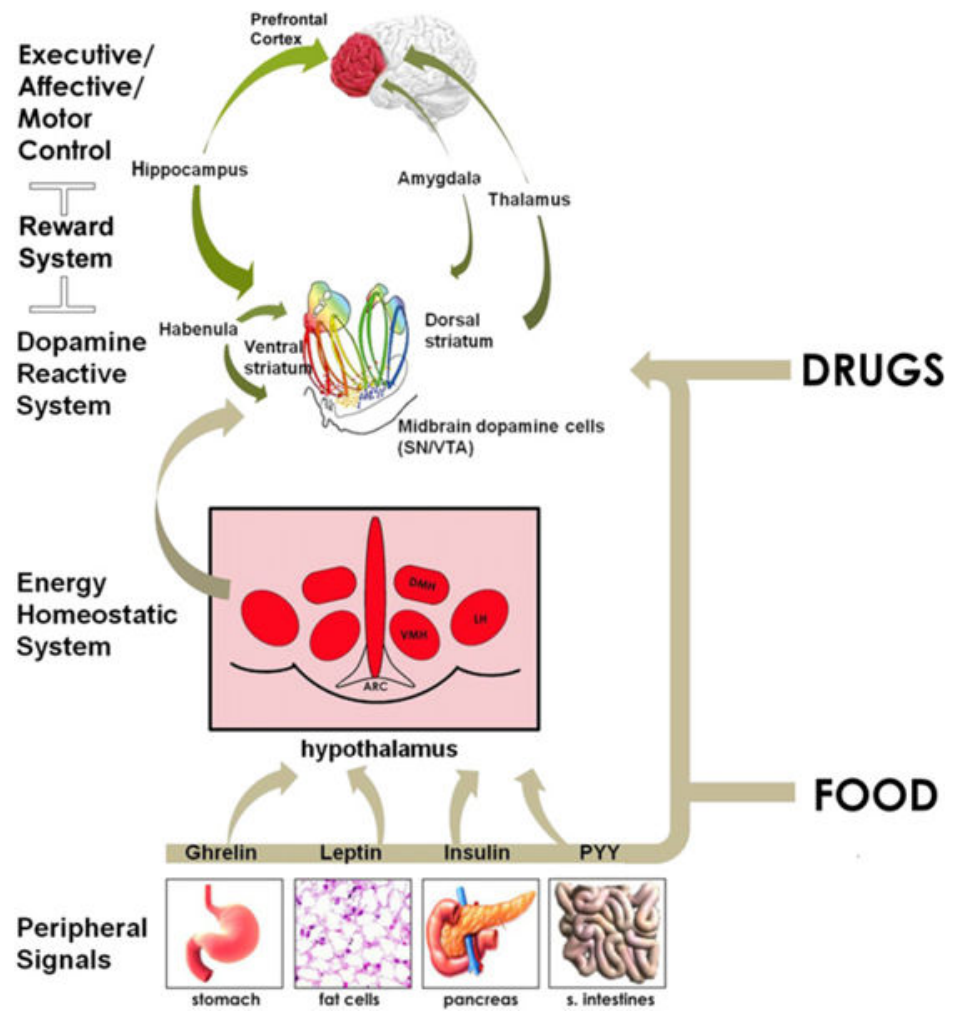

Figure 1.

In striking contrast to drugs whose actions are triggered by their direct pharmacologic effects in the brain reward dopamine pathway (ventral tegmental area [VTA], nucleus accumbens, and ventral pallidum), the regulation of eating behaviors and hence the responses to food are modulated by multiple peripheral and central mechanisms that directly or indirectly convey into the brain's reward pathways, including those involved with pleasure, aversion, habituation, and cognitive control [Diagram of the organization of striatocortical connectivity loops reprinted with permission from Haber et al. (112), copyright 2000 Society for Neuroscience]. PYY, peptide YY; s. intestines, small intestines; $\mathrm{SN}$, substantia nigra. 

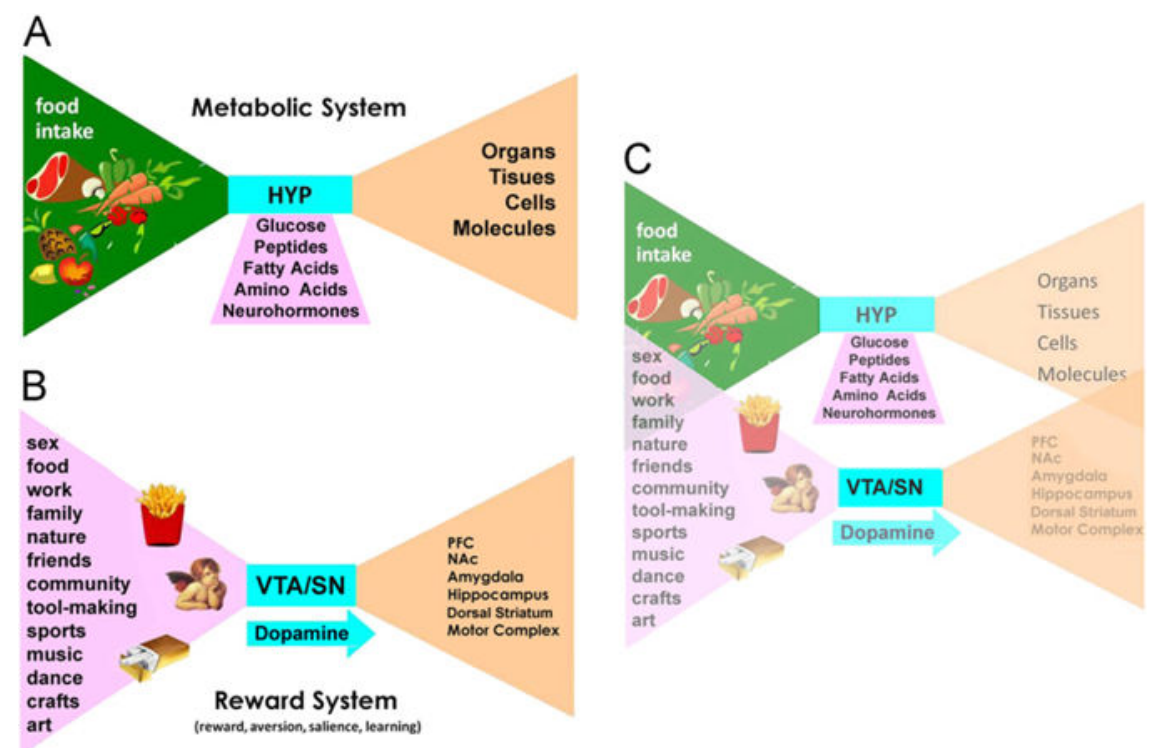

Figure 2.

Schematic representation of bowtie architectures in the brain as exemplified by the (A) energy homeostatic (metabolic) and (B) dopamine reactive (reward) systems. The human brain, like most complex biological systems, is characterized by the layered architectures of interactive networks [reprinted with permission from (111), copyright 2004 Elsevier]. These systems display an evolutionarily optimized organization, whereby a narrowing funnel of many potential inputs converges onto a relatively small number of processes before fanning out again into a great diversity of outputs. (C) The homeostatic and reward bowties are good examples of nested layered architectures [reprinted with permission from (111), copyright 2004 Elsevier], since the dopamine bowtie can be viewed as an integral part of the broader energetic network that includes hypothalamic (HYP) signaling and peripheral hormones. NAc, nucleus accumbens; PFC, prefrontal cortex; SN, substantia nigra; VTA, ventral tegmental area (modified with permission from an unpublished presentation, courtesy of Dr. John Doyle, Ph.D.). 


\section{Table 1}

\section{Some Open Questions for Future Research on the Addictive Aspects of Obesity}

- Do imbalances between D1 receptor signaling (enhanced) and D2 receptor signaling (decreased), which facilitate compulsive drug intake, also favor compulsive food intake?

- To what extent is striatal D2 receptor dysfunction a clinical consequence of drug use or obesogenic diets as opposed to being a marker of differential vulnerability in addiction/obesity?

- What are the lessons, if any, that obesity research can derive from successful addiction prevention and treatment approaches? For example, are the cortical areas involved in inhibitory control (dorsolateral prefrontal cortex and anterior cingulate cortex) potential substrates for behavioral retraining in the treatment of addiction/obesity?

- Genetic research to explore the potential contribution of genes that influence personality (e.g., perseverance, sustained physical activity, and executive control traits) to obesogenic behaviors.

- What are the underlying biological mechanisms linking bariatric surgery to increased risk of alcoholism?

- What are the specific roles of the stress reactivity and antireward system in connecting dysphoric, negative affect, or stressful states with compulsive eating?

- $\quad$ Longitudinal studies are needed to investigate whether and how early food and lifestyle choices are associated with later body mass index and executive functioning. 